\author{
Tai-Yuan Chiu \\ Wen-Yu Hu \\ Ching-Yu Chen
}

\section{Prevalence and severity of symptoms in terminal cancer patients: a study in Taiwan}

Published online: 17 January 2000 (C) Springer-Verlag 2000

T.-Y. Chiu, M.D., M.H.Sci. (西)

W.-Y. Hu, R.N., M.S.N.

Ching-Yu Chen, M.D.

Hospice and Palliative Care Unit, Department of Family Medicine, National Taiwan University Hospital, No. 7, Chung-Shan South Road, Taipei, Taiwan e-mail: tychiu@ha.mc.ntu.edu.tw

Tel.: + 886-2-23562878

Fax: + 886-2-23118674

W.-Y. Hu, R.N., M.S.N.

Department of Nursing Science, Medical College, National Taiwan University,

Taipei, Taiwan

C.-Y. Chen, M.D.

Department of Family Medicine, Medical College, National Taiwan University,

Taipei, Taiwan

\begin{abstract}
This paper reports a prospective study conducted between September 1997 and July 1998 in 232 consecutive patients with terminal cancer. A structured data collection form was used daily to evaluate symptoms, which were analyzed at the time of admission, 1 week after admission and $48 \mathrm{~h}$ before death. Terminal cancer patients in this study were polysymptomatic. There were no statistically significant differences in the prevalence of most symptoms with the primary site of cancer. The majority of symptoms improved at the end of the 1st week after admission, but many symptoms worsened just before death. The high preval-
\end{abstract}

ence of symptoms and lack of significant difference among primary tumor sites may be related to shorter survival times caused by late referral, which is common in Taiwan.

Key words Taiwan - Symptom · Prevalence $\cdot$ Terminal cancer

\section{Introduction}

The prevalence of symptoms in patients with terminal cancer varies considerably $[4,5,9]$. This variation in symptom prevalence may be due to differences in study design, patient selection and cancer staging. Cancer sites associated with different ethnic groups may also affect the prevalence and severity of symptoms [9]. Over the last decade the hospice and palliative care services have expanded in Taiwan, and it is important to know what symptoms are distressing terminal cancer patients in Taiwan.

\section{Patients and methods}

A prospective study was undertaken in 232 consecutive patients admitted to the Hospice and Palliative Care Unit at National Tai- wan University Hospital from September 1997 to July 1998. Patients who were not responsive to curative treatment were identified in an initial assessment performed by members of the admissions committee.

The assessment tool used was a recording form designed by experienced specialists. It included demographic data, pain and dyspnea scores (on a scale of 0-10), and scores for common symptoms other than pain and dyspnea $(0=$ none; $1=$ mild; $2=$ moderate; $3=$ severe). The study also assessed common problems encountered in terminal care, including ulcerated wounds, ascites, pleural effusion and edema (which, though basically signs, can be accompanied by symptoms). The prevalence of these symptoms was recorded daily by the same staff members who assessed and recorded the presence or absence of symptoms and their severity and subsequently analyzed for the time of admission, 1 week after admission, and $48 \mathrm{~h}$ before death.

The percentage of patients with each symptom and the mean severity scores were examined. The Chi-square test and Student's $t$-test were used for comparisons. A probability of less than 0.05 was considered significant. 


\section{Results}

There were 115 (49.6\%) male patients and 117 (50.4\%) female. The mean age of all patients was $62.1 \pm 15.8$ years. Fifty $(21.6 \%)$ patients had lung cancer. Other primary sites included liver $(10.8 \%)$, colon and rectum $(10.8 \%)$, stomach $(9.5 \%)$, head and neck $(6.9 \%)$, cervix and uterus $(4.3 \%)$, breast $(4.3 \%)$ and pancreas $(4.3 \%)$. The mean length of hospitalization was $13.7 \pm 11.5$ days. By the end of the study period 189 $(81.5 \%)$ patients had died; their median survival time was 13 days.

Patients averaged 9.1 symptoms each at the time of admission. The prevalence of some of the symptoms in all patients at admission (Table 1) was: weakness $(82.3 \%)$, pain $(81.0 \%)$, anorexia $(81.0 \%)$, and weight loss $(64.7 \%)$; these were the predominant symptoms of cancer in most primary sites. Patients with lung cancer had a higher prevalence of dyspnea $(60.0 \%)$ and of mental change $(58.0 \%)$. Symptoms of dysphagia and nausea/vomiting were common among patients with stomach or colo-rectal cancer. Edema, ascites and nausea/vomiting were predominant in liver cancer, while dyspnea, edema, and depression were the predominant symptoms among those with uterine cancers. All patients with pancreatic cancer had pain, and dyspnea was frequent. Dysphagia was predominant in head and neck cancers, as were depression and ulceration.

After 1 week in the hospice most symptoms improved. The mean scores for pain, dysphagia, confusion, and fever improved markedly $(P<0.05)$. However, all symptoms except pain, fever, weight loss, and nausea/vomiting tended to worsen in the $48 \mathrm{~h}$ before death (Table 2).
Table 2 Change in severity of symptoms from the time of admission $^{\mathrm{a}}$

\begin{tabular}{|c|c|c|c|}
\hline \multirow[t]{2}{*}{ Symptoms } & \multicolumn{3}{|l|}{ Severity } \\
\hline & 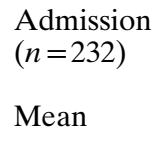 & $\begin{array}{l}\text { One week } \\
\text { later } \\
(n=153) \\
\text { Mean }(P)^{\mathrm{b}}\end{array}$ & $\begin{array}{l}\text { Two days } \\
\text { before death } \\
(n=187) \\
\text { Mean }(P)^{\mathrm{c}}\end{array}$ \\
\hline Pain & 3.26 & $2.31(0.00)^{*}$ & $2.23(0.00)^{*}$ \\
\hline Dyspnea & 2.02 & $1.60(0.11)$ & $3.02(0.00)^{*}$ \\
\hline Weakness & 1.65 & $1.54(0.60)$ & $2.07(0.00)^{*}$ \\
\hline Anorexia & 1.62 & $1.51(0.83)$ & $2.00(0.01)^{*}$ \\
\hline Weight loss & 1.58 & $1.42(0.32)$ & $1.46(0.32)$ \\
\hline Dysphagia & 1.04 & $1.03(0.03)^{*}$ & $1.54(0.00)^{*}$ \\
\hline Edema & 0.94 & $0.78(0.29)$ & $1.27(0.00)^{*}$ \\
\hline Confusion & 0.92 & $0.85(0.03)^{*}$ & $1.88(0.00)^{*}$ \\
\hline Nausea/vomiting & 0.81 & $0.73(0.16)$ & $0.69(0.02)^{*}$ \\
\hline Depression & 0.80 & $0.93(0.05)$ & $0.99(0.01)^{*}$ \\
\hline Constipation & 0.79 & $0.75(0.37)$ & $0.82(0.72)$ \\
\hline Restlessness & 0.76 & $0.74(0.70)$ & $1.18(0.00)^{*}$ \\
\hline Insomnia & 0.73 & $0.61(0.05)$ & $0.78(0.71)$ \\
\hline Ascites & 0.66 & $0.55(0.59)$ & $0.83(0.02)^{*}$ \\
\hline Dry mouth & 0.57 & $0.56(0.57)$ & $0.82(0.00)^{*}$ \\
\hline Jaundice & 0.53 & $0.44(0.61)$ & $0.71(0.07)$ \\
\hline Pleural effusion & 0.46 & $0.29(0.48)$ & $0.50(0.45)$ \\
\hline Bleeding & 0.39 & $0.34(0.47)$ & $0.59(0.04)^{*}$ \\
\hline Fever & 0.37 & $0.22(0.04)^{*}$ & $0.38(0.64)$ \\
\hline Ulcerated wound & 0.31 & $0.39(0.18)$ & $0.33(0.32)$ \\
\hline Hallucination & 0.11 & $0.17(0.05)$ & $0.33(0.00)^{*}$ \\
\hline
\end{tabular}

$* P<0.05$

${ }^{\text {a }}$ The severity of pain and dyspnea were scored using a 10-point scale; other symptoms were scored using a 3-point scale; 0 none, 1 mild, 2 moderate, 3 severe

${ }^{\mathrm{b}}$ Comparison between admission and 1 week later

${ }^{\mathrm{c}}$ Comparison between admission and 2 days before death

\section{Discussion}

The proportions of primary tumors found in this study mirrored cancer mortality in Taiwan [6] except for liver

Table 1 Prevalence of symptoms at the time of admission by primary site of cancer. Chi-square test, $d . f .=8(N / V$ nausea and vomiting)

\begin{tabular}{|c|c|c|c|c|c|c|c|c|c|c|c|}
\hline \multirow[t]{2}{*}{ Primary site } & \multicolumn{10}{|c|}{ Symptoms (\%) } & \multirow[t]{2}{*}{ No. } \\
\hline & Weakness & Pain & Anorexia & Weight loss & Dysphagia & Dyspnea & $\begin{array}{l}\text { Restless- } \\
\text { ness }\end{array}$ & Confusion & $\mathrm{N} / \mathrm{V}$ & Insomnia & \\
\hline Lung & 80.0 & 78.0 & 76.0 & 69.4 & 48.0 & 60.0 & 52.0 & 58.0 & 42.0 & 48.0 & 50 \\
\hline Colon and rectum & 62.5 & 79.4 & 91.7 & 60.9 & 62.5 & 45.8 & 58.3 & 25.0 & 55.0 & 45.8 & 25 \\
\hline Liver & 83.3 & 70.8 & 85.3 & 58.3 & 41.7 & 58.3 & 37.5 & 52.0 & 62.5 & 45.8 & 25 \\
\hline Stomach & 86.4 & 90.9 & 91.0 & 71.0 & 59.1 & 54.5 & 54.5 & 45.5 & 59.1 & 59.1 & 22 \\
\hline Head and neck & 75.0 & 87.5 & 56.2 & 67.5 & 68.7 & 37.5 & 37.5 & 43.7 & 25.0 & 25.0 & 16 \\
\hline Cervix & 90.0 & 60.0 & 90.0 & 70.0 & 50.0 & 80.0 & 30.0 & 50.0 & 40.0 & 50.0 & 10 \\
\hline Breast & 70.0 & 70.0 & 90.0 & 70.0 & 70.0 & 60.0 & 70.0 & 80.0 & 50.0 & 50.0 & 10 \\
\hline Pancreas & 80.0 & 100.0 & 90.0 & 80.0 & 60.0 & 60.0 & 60.0 & 40.0 & 60.0 & 40.0 & 10 \\
\hline Others & 81.2 & 78.1 & 79.7 & 62.5 & 56.2 & 48.4 & 51.6 & 50.0 & 48.4 & 42.2 & 64 \\
\hline Total & 82.3 & 81.0 & 81.0 & 64.7 & 54.7 & 53.4 & 50.0 & 48.7 & 48.3 & 44.8 & 232 \\
\hline$P$-value & 0.662 & 0.478 & 0.125 & 0.861 & 0.644 & 0.483 & 0.511 & 0.168 & 0.414 & 0.751 & \\
\hline
\end{tabular}


cancer, which in this study had a lower mortality rate than that in the general population of Taiwan $(10.8 \%$ vs $20.4 \%$ ). The relatively younger age of liver cancer patients may have influenced the motivation of these patients to opt for palliative care.

In this study, the prevalence of all symptoms on admission was considerably higher than in previous studies $[3,5,9]$. This difference may indicate inadequate symptom control before admission or late referral for palliative care. There were no statistically significant differences between the primary cancer sites and the prevalence of symptoms; this may be related to the shorter survival time and could be explained with reference to the "terminal common pathway" in cancer patients $[8,9]$.

The most frequent symptom in this study was weakness, which was observed in $82.3 \%$ of the patients, a higher frequency than the $50 \%$ reported in the study by Walsh and Saunders [10] and the $75 \%$ reported by Bruera and MacDonald [2]. Weakness was common with cancer in all primary sites $(P=0.662)$. Weakness and fatigue distress patients and reduce their quality of life. This did not improve significantly after 1 week of intensive care.

Pain was the second commonest symptom (81\%). A little over one-third of the patients rated their pain as moderate to severe $(35.4 \%)$. The severity of pain had diminished significantly at the end of the 1st week after admission and $48 \mathrm{~h}$ before death. Better pain control has been achieved following the introduction of educational programs on analgesia, which have been implemented since 1990 in Taiwan.

The prevalence of anorexia was $81 \%$, higher than in earlier studies [7, 9]. Loss of appetite is difficult to measure, and families in Taiwan almost always ask for parenteral hydration or nutrition when patients begin to lose their appetites. This raises frequent ethical dilemmas in Oriental countries. Both weakness and anorexia may be related to metabolic dysfunction leading to cachexia in patients with advanced cancer [1]. Along with weakness and anorexia, cachexia can also produce psychological distress in patients and families. Overuse of parenteral nutrition and albumin often occurs because of family anxiety.

More than half the patients experienced dysphagia. Dedicated mouth care and feeding instructions may improve swallowing function so that the use of nasogastric tubes is not so often necessary as it otherwise might be. The severity of dysphagia diminished 1 week after admission.

The prevalence of dyspnea was $53.4 \%$, and it was most common in lung cancer. Nearly one-quarter of the patients described their dyspnea as moderate or severe, and it was often poorly controlled and only slightly improved after 1 week of care.

In summary, terminal cancer patients were polysymptomatic; weakness, pain, anorexia, and cachexia were the most frequent symptoms of cancer in all primary sites. These symptoms distressed the patients and reduced their quality of life. These results should persuade the authorities in countries in our region to expand education, research and services in specialist palliative care more aggressively. There were no statistically significant differences in the prevalence of most symptoms with primary cancer site. This may be related to the extremely short survival of our patients, which is attributable mainly to late referral. The causes of late referral require investigation and intervention. Most symptoms became worse and difficult to control near to death. Symptom control and care of the dying in terminal cancer remains a challenge to palliative care specialists in Taiwan.

Acknowledgements This research was supported by a grant from the National Science Council, Taiwan. We are indebted to the medical and nursing staff of the Department of Family Medicine at National Taiwan University Hospital, and also to Ms. C.T. Wang and Ms. C.H. Teng for secretarial support.

\section{References}

1. Bruera E (1997) ABC of palliative care: cachexia and nutrition. BMJ 315:1219-1222

2. Bruera E, MacDonald RN (1988) Asthenia in patients with advanced cancer. J Pain Symptom Manage 1:9-14

3. Conill C, Verger E, Henriquez I, et al (1997) Symptom prevalence in the last week of life. J Pain Symptom Manage 14:328-331
4. Coyle N, Adelhardt J, Foley KM, Portenoy RK (1990) Character of terminal illness in the advanced cancer patient: pain and other symptoms during the last four weeks of life. J Pain Symptom Manage 5:83-93

5. Curtis EB, Krech R, Walsh D (1991) Common symptoms in patients with advanced cancer. J Palliat Care 7:25-29

6. Department of Health, The Executive Yuan, Republic of China (1997) Vital statistics, Republic of China,Taipei. Department of Health, The Executive Yuan, Taipei
7. Dunlop GM (1989) A study of the relative frequency and importance of gastrointestinal symptoms, and weakness in patients with advanced cancer: student's paper. Palliat Med 4:37-43

8. Lichter I, Hunt E (1990) The last 48 hours of life. J Palliat Care 6:7-15

9. Vainio A, Auvinen A (1996) Prevalence of symptoms among patients with advanced cancer: an international collaborative study. J Pain Symptom Manage 12:3-10

10. Walsh T, Saunders C (1984) Hospice care: the treatment of pain in advanced cancer. Recent Results Cancer Res 89:201-211 